Original Article

\title{
Assessment of Knowledge, Attitude and Dietary Practices among rural school children around Mangalore - An Epidemiological Survey
}

\author{
Amitha M. Hegde ${ }^{1}$, Tanvi Shah ${ }^{2}$, Sherin Sara George ${ }^{3}$, Priyanka K.K. ${ }^{4}$ \\ ${ }^{1}$ Professor and Head, 2, 3, ${ }^{4}$ Post Graduate, Department of Pedodontics and Preventive dentistry, A.B. Shetty Memorial \\ Institute of Dental Sciences, Deralakatte, Mangalore, Karnataka.
}

*Corresponding Author: Amitha M. Hegde, Professor \& Head, Department of Pedodontics and Preventive dentistry, A.B. Shetty Memorial Institute of Dental Sciences, Deralakatte, Mangalore, Karnataka.

Mobile : +919886764015 E-mail : tanvishah88@ gmail.com

Received : 27-01-2016

Review Completed : 01-08-2016

Accepted

: 05-08-2016

Keywords : Diet, Nutrition, Junk food, Children

\begin{tabular}{|c|}
\hline Access this article online \\
\hline Quick Response Code \\
\hline
\end{tabular}

Abstract:

Aim and Objectives : Healthy eating habits are essential not only for overall physical health, but also for the development and maintenance of a healthy oral cavity. Evidences indicate that dietary habits acquired in childhood persist through to adulthood, and the family and community have important roles to play in acquisition of nutrition related knowledge and practices. The purpose of this study was to survey the knowledge, attitudes and the eating practice of nutritious and junk food among rural school children and to assess any improvement in the attitudes and eating behaviours of the children with increasing level of knowledge.

\begin{abstract}
Materials and Methods : The questionnaire survey was conducted in eight government schools around Mangalore which included a sample population of 2,355 children divided into two groups. Group 1 consisted of Class V to Class VII and Group 2 of Class VIII to Class X. A questionnaire consisting of seventeen multiple choice questions to assess the knowledge, attitude and daily consumption of nutritional as well asjunk foods was used.

Results and Conclusion : Our survey found that although there was better knowledge and attitude among the older children belonging to Group 2, there was an increased preference for junk foods among both the younger and older children alike, the taste and visual appeal being the major reasons. Despite increased awareness, consumption of junk food was still prevalent among the vast majority in all age groups.
\end{abstract}

\section{Introduction}

Healthy eating habits are essential not only for overall physical health, but also for the development and maintenance of a healthy oral cavity. When there is a lack of one or more nutrients in our diet, the first symptoms of deficiency often manifest in the oral cavity. Diet plays a significant etiological role not only in development of dental caries, but even dental erosion, developmental defects of teeth, periodontal diseases and oral cancer.

As per the 'Dietary Guidelines for Indians, 2011' of the National Institute of Nutrition (NIN), a balanced diet is one which provides all the nutrients in required amounts and proper proportions; and unhealthy(junk) foods are those containing little or no proteins, vitamins or minerals but are rich in salt, sugar, fats and are high in energy(calories).

The family and community play an important role in the acquisition of nutrition knowledge and nutrition related practices. Evidences indicate that dietary habits acquired in childhood persist through to adulthood. ${ }^{1}$ Furthermore, research also indicates a role for childhood nutrition on adult health. ${ }^{2}$ the school is one of the main social contexts in which lifestyles are developed. There has been an evolution in food habits with the replacement of healthy nutritious foods with things that are tasty, convenient, in vogue-junk food. These are foods that are rich in salt, sugar and fat or calories, but low nutrient content. ${ }^{3}$ the changing lifestyles and the easy availability of junk food near schools or even within school canteens have led children to prefer 
and become addicted to junk foods.

Epidemiological surveys in India have shown the increasing oral health problems among the rural children, especially due to limited access to oral health care services. ${ }^{4}$ A study has also shown that children in rural schools liked junk foods and they preferred to have them in between meals. ${ }^{5}$

The purpose of this study was to survey the knowledge, attitudes and the eating practice of nutritious and junk food among rural school children and to assess any improvement in the attitudes and eating behaviours of the children with increasing level of knowledge.

\section{Materials And Methods \\ Study Population}

This survey was conducted in eight government schools around $M$ angalore over a period of one month. The sample population included 2,355 children from Class V to Class X which were divided into two groups. Group 1 consisted of Class V to Class VII and Group 2 of Class VIII to Class X. Out of the population, 1,120 were girls and 1,235 were boys with age between 9 to 15 years.

\section{Questionnaire}

A questionnaire containing a set of seventeen multiple choice questions was prepared and distributed in the children's native language. This questionnaire aimed to assess the knowledge, attitude and daily consumption of nutritional as well as junk foods. The children's responses were collected and manually assessed based on the choice specified for each question framed.

The answers pertaining to knowledge based questions were graded as correct and wrong answers. The attitude of the children was assessed with choices as yes, no or don't know. The questionnaire also included questions on the preference and frequency of consumption of nutritious and junkfoods.

\section{Results}

\section{Assessment of knowledge}

The knowledge among the children in Group 2 was found to be better than that among children in Group 1. For the nutrition based questions, 44\% students in Group 1 and 83\% in Group 2 answered correctly (Figure 1). 36.2\% students in Group 1 and 63.82\% students in Group 2 gave correct answers to questions assessing knowledge on junk food (Figure 2).

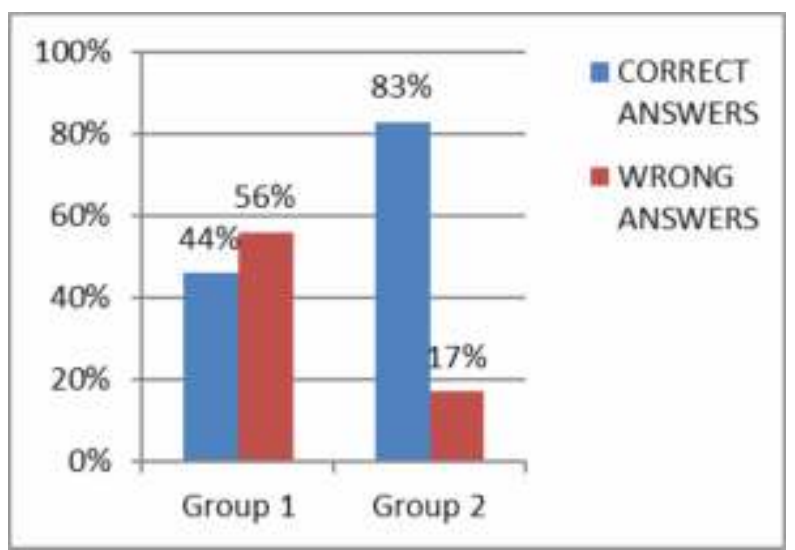

Figure 1 : Assessment of knowledge on nutritious food

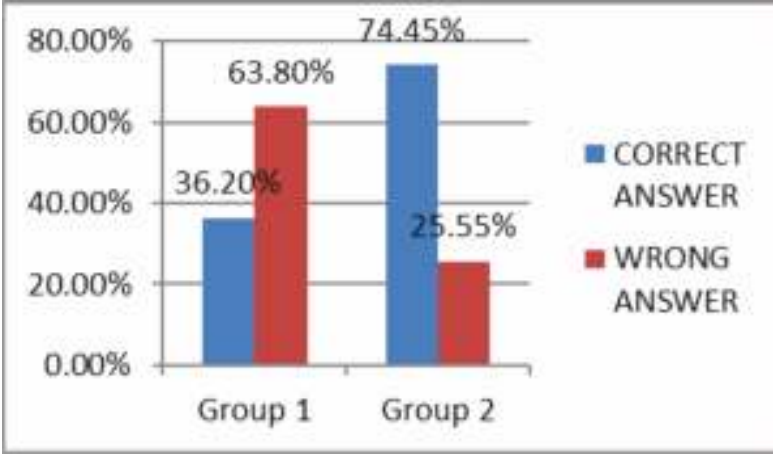

Figure 2 : Assessment of knowledge on junk foods

\section{Assessment of attitude}

The attitude of the children was assessed by the answers to four questions as yes, no or don't know. In Group 1, only $15.21 \%$ felt the need to know about nutrition whereas 94.36\% agreed in Group 2. $70.51 \%$ in Group 1 and $45.27 \%$ in Group 2 felt that they didn't need to worry about their food intake as they were too young. 44.66\% in Group 1 and $84.54 \%$ in Group 2 felt that having breakfast was important. Among Group 1, 58.24\% and 34.72\% among Group 2 felt that eating healthy food is essential only when sick (Figure 3). 


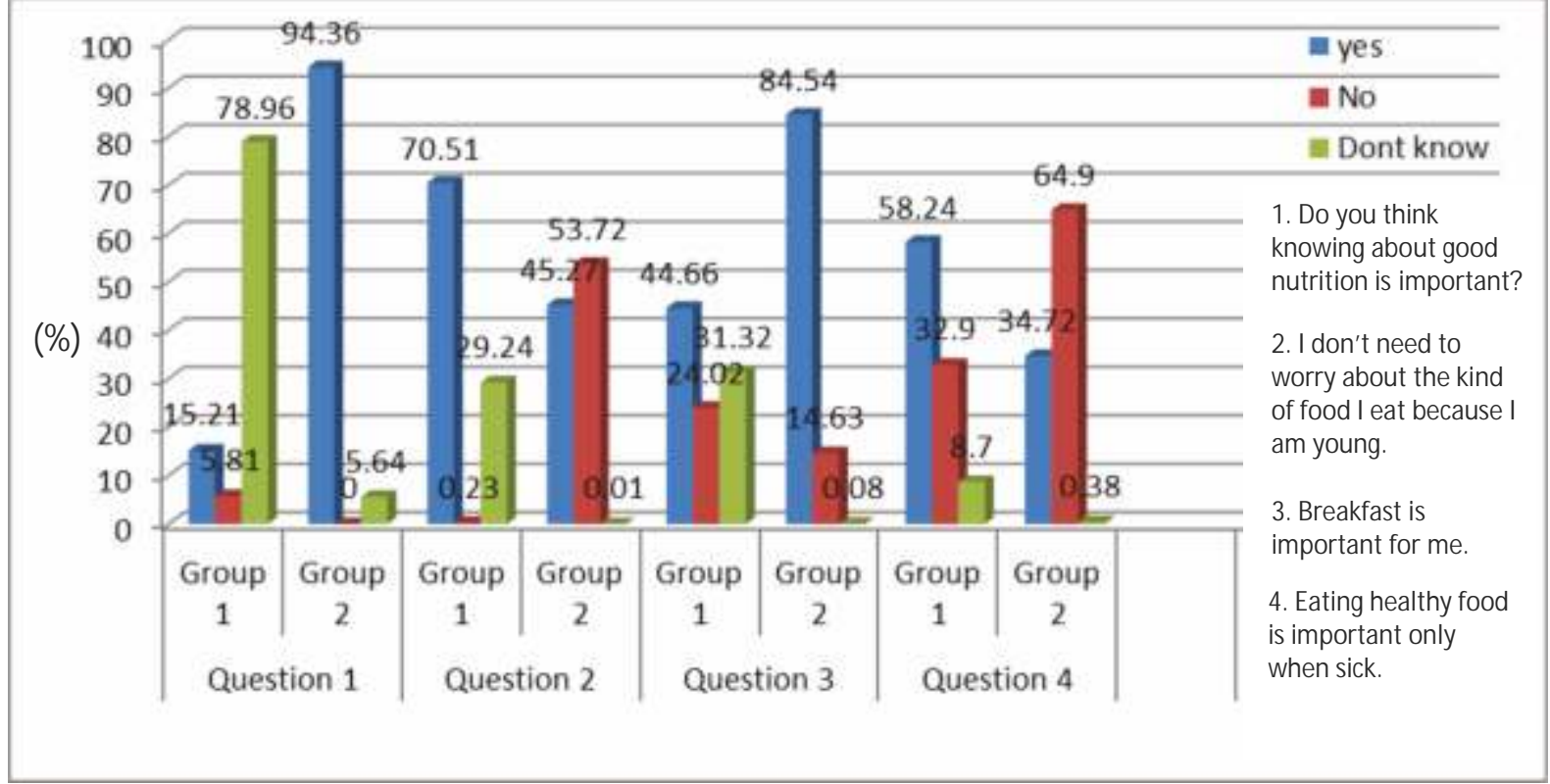

Figure 3 : Assessment of attitude

When asked about preferences between homes cooked food and junk food, majority (73.27\%) in Group 1 preferred home cooked food whereas only $40.54 \%$ did so in Group 2. The reasons for their preferences were varied. Taste of the food as well as the visual appeal scored higher than the nutritional value as shown in figure 4 .

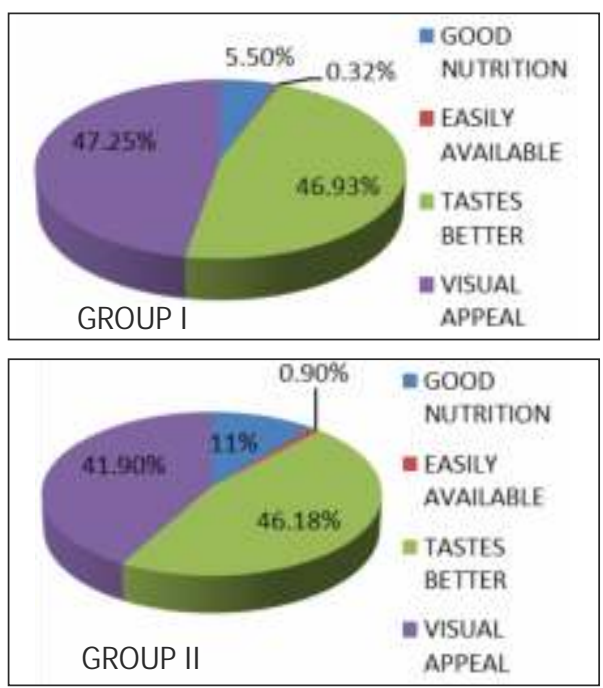

Figure 4 : Reasons for preference for junk food

\section{Assessment of eating practice}

Among Group 1, a predilection towards chocolates and candies (43.18\%) closely followed by soft drinks and colas (33.46\%), snacks ( $15.37 \%)$ and fast foods $(7.68 \%)$ was seen. In Group 2 the choice of junk food was soft drinks (41.27\%) followed by chocolates and candies(37.45\%), snacks
(12.18\%) and fast food (8.18\%)(Figure 5).

Though legumes, milk and vegetables formed a part of daily diet, junk foods too were consumed frequently. 38.89\% and 35.8\% in Group 1 and Group 2, respectively, ingested them once daily whereas 39.55\% in Group 1 and 15\% in Group 2 consumed junk foods more than once a day. Fruits were consumed daily only by a minority in both the groups. (Table 1)

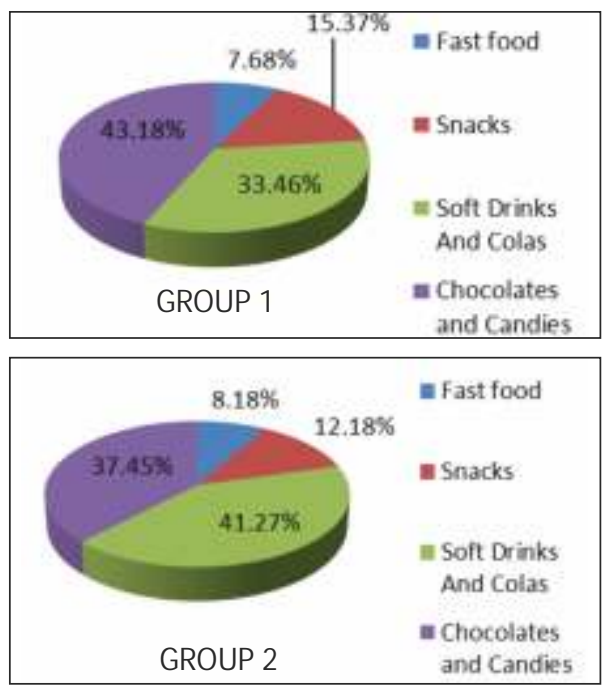

Figure 5 : Choice of junk food 


\begin{tabular}{|l|c|c|c|c|c|c|c|c|}
\hline & \multicolumn{2}{|c|}{ Didn't have } & \multicolumn{2}{c|}{ Once/ twice a week } & \multicolumn{2}{c|}{ Everyday } & \multicolumn{2}{c|}{ More than once daily } \\
\hline & Group1 & Group2 & Group1 & Group2 & Group1 & Group2 & Group1 & Group2 \\
\hline Cereals and Legumes & 0 & 0 & $4.02 \%$ & 0 & $83.02 \%$ & $91.2 \%$ & $12.96 \%$ & $8.8 \%$ \\
\hline Milk & 0 & 0 & 0 & $2.76 \%$ & $97.09 \%$ & $92.14 \%$ & $2.91 \%$ & $5.09 \%$ \\
\hline Vegetables & 0 & 0 & $7.56 \%$ & $5.96 \%$ & $72.52 \%$ & $78.80 \%$ & $19.92 \%$ & $15.24 \%$ \\
\hline Fruits & $11.89 \%$ & $19.4 \%$ & $78.82 \%$ & $72.4 \%$ & $9.29 \%$ & $8.2 \%$ & 0 & 0 \\
\hline Junk food & $0.93 \%$ & $7.43 \%$ & $20.63 \%$ & $41.77 \%$ & $38.89 \%$ & $35.8 \%$ & $39.55 \%$ & $15 \%$ \\
\hline
\end{tabular}

Table 1 : Dietary Practices

\section{Discussion}

The eating behaviours that children practice early in life affect their health and nutrition, and may continue to shape food attitudes and eating patterns throughout adulthood. ${ }^{6}$

As per this study, the knowledge about nutritious as well as junk foods increased with the age of the children and their years of school. Although a majority of children in the older age group knew the importance of nutrition, it was interesting to note that a large number believed that they were too young to bother about the kind of food they consumed. This could be probably because their food choices are either made by their parents or by their school. Joshi et $\mathrm{al}^{7}$ evaluated the role of sociodemographic characteristics of mother on the nutritional status of the child and concluded that literacy and social status of the parent are key factors contributing to malnutrition in children and that prevalence can be reduced by increasing awareness.

In the present study it was noted that despite increased knowledge and better attitude among older children; only less than half, preferred home cooked food compared to a large majority in younger age group. The reason for this disparity might be because of the early exposure to junk food by the parents in order to pacify them and the added influence of TV adds. Also improved marketing strategies and increased transport facilities have brought food materials like chocolates to even the remotest villages and made them easily accessible. This could lead to early addiction and development of taste preferences in older children.

Our study revealed that taste and visual appeal as opposed to nutritional value and availability were responsible for the preference of junk foods among both the groups of children.

Similar study conducted by Kotecha et al ${ }^{8}$ concluded that nutrition behaviour is influenced more by taste, availability of foods and peer pressure, and less by knowledge.

Our study showed an increased inclination in the younger age group towards chocolates and candies followed by soft drinks, and vice versa in older age group whereas snacks and fast foods were not much preferred. On the contrary, a study done by Gopal $V$ et $a l^{9}$ among urban adolescents reported an increased preference for fast foods and snacks as opposed to soft drinks and candies. Thus a change in the preference for the type of junk food is seen among different age groups and urban/ rural settings.

Majority of children in both the groups in our study consumed basic nutritious food like cereals and legumes, milk and vegetables on a daily basis. This could be because their main meals are taken either at home or are provided at school. Fruits are the essential nutritional component which were seen to be lacking in the daily diet and were consumed only once or twice a week. However, notew orthy was the fact that junkfoods were consumed by both the groups of children on a daily basis. Thus it is important to reinforce the benefits of consuming nutritious food and outlining the side effects of junk foods on a regular basis.

\section{Conclusion}

The knowledge about nutrition and junk food increased with age and years of schooling, and a better attitude was seen among the older children concerning the importance of nutrition in daily diet. Despite increased awareness, consumption of junk food was still prevalent among the vast majority in all age groups. 


\section{Recommendations}

1. The first step to be taken is to counsel the parents and teachers along with the students.

2. Parents should be advised not to succumb to the children's demands for junk food on a daily basis

3. A balanced meal should be provided either by parents or at school and the accessibility to junk foods near school grounds should be minimised.

4. Communities, schools, movies, television, and food companies should partner in promoting healthy food choices. The Government should encourage advertisement of healthy food which can create interest among the child viewers.

\section{References}

1. Kelder SH, Perry CL, Klepp K-I, Lytle LL. Longitudinal tracking of adolescent smoking, physical activity and food choice behaviours. Am J Public Health 1994; 84: 1121-1126

2. Berenson GS, Srinivasan SR, Bao W, Newman WP III, Tracey RE, Wattigney WA. Association between multiple cardiovascular risk factors and atherosclerosis in children and young adults. N Engl J M ed 1998; 338: 1650-1656

3. Anderson W, Patterson. Snack foods: Comparing nutrition values of excellent choices and 'Junk foods', Metabolic Research Group, University of Kentucky, Lexington.

4. Kumar SA, Kumar PDM, Sivasamy S, Balan IN. Oral health status of 5 and 12 year old rural school going children with limited access to oral health care - a cross sectional survey. CaribJ Sci Tech 2014; 2: 336-339

5. Kaur M, Hegde AM. Are we aware of what we are - we are aware of what we eat - an epidemiological survey. Jaypee's Int J of Clin Ped Dent. Sep-Dec 2008; 1(1):13-16

6. Campbell K, Crawford D. Family food environments as determinants of preschool-aged children's eating behaviours: Implications for obesity prevention policy. A review. AustJ Nut and Diet 2001; 58(1):19-25

7. Joshi HS, Gupta R, Joshi MC, Mahajan V. Determinants of nutritional status of school children - a cross sectional study in the western region of Nepal. NatJ Integ Res M ed 2011; 2(1): 10-15

8. Kotecha et al. D Dietary pattern of school going adolescents in urban Baroda, India.J Health Popul Nutr 2013 Dec;31(4):490-496

9. Gopal V, Sriram S, Kannabiran K, Seenivasan R. Student's perspective on junk foods: Survey. Sud J Pub Health 2012. Jan ; 7(1):21-25
5. Parents can be guided to make the nutritional food tastier and visually appealing so that it is easily accepted bythe children.

\section{Limitations of the Study}

- Children are not the key decision makers on nutrition practices in school and at home hence most of their nutritional practices were not dependent on their choices.

- In addition, information on practices was self reported by children and not based on observation and may be influenced by what is ideal as compared to the facts.

- The answers given by the students may also be influenced by the answers of their peers. 